\title{
Evaluation of wear performance of cryogenically treated Vanadis 4 Extra tool steel
}

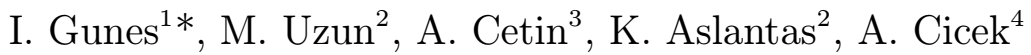 \\ ${ }^{1}$ Afyon Kocatepe University, Faculty of Technology, Department of Metallurgical and Materials Engineering, \\ 03200 Afyonkarahisar, Turkey \\ ${ }^{2}$ Afyon Kocatepe University, Faculty of Technology, Department of Mechanical Engineering, Afyonkarahisar, Turkey \\ ${ }^{3}$ Sakarya University, Sakarya Vocational School of Higher Education, Sakarya, Turkey \\ ${ }^{4}$ Ylldırım Beyazıt University, Faculty of Engineering and Natural Sciences, Department of Mechanical Engineering, \\ Ankara, Turkey
}

Received 1 December 2014, received in revised form 23 March 2015, accepted 7 October 2015

\begin{abstract}
In this study, the wear performance of cryogenically treated cold-work tool steel (Vanadis 4 Extra) samples was evaluated in the light of some sliding wear tests. For this purpose, the samples were cryogenically treated for different durations $(0,1,12$, and $24 \mathrm{~h})$ at deep cryogenic temperature $\left(-145^{\circ} \mathrm{C}\right)$. A tempering process was performed at two different temperatures (175 and $525^{\circ} \mathrm{C}$ ) for $2 \mathrm{~h}$. The wear experiments were carried out in a ball-on-disk tester, by applying two loads of 10 and $20 \mathrm{~N}$ and a sliding velocity of $0.3 \mathrm{~m} \mathrm{~s}^{-1}$. Experimental results showed that samples treated for $24 \mathrm{~h}$ and tempered at $525^{\circ} \mathrm{C}$ exhibited the best wear performance. This can be explained by the increasing hardness value as a result of the nearly full transformation of retained austenite to martensite, the formation of fine carbide particles and homogeneous distribution of carbides. The hardness measurements and XRD analysis confirmed the wear test results.
\end{abstract}

Key words: Vanadis 4 Extra, cryogenic treatment, microstructure, wear resistance

\section{Introduction}

Tool steels are the high-quality steels used to manufacture the tools, die and molds that shape, form and cut different engineering materials such as steels, nonferrous materials and plastics [1]. In many industrial applications, tool steels are subjected to extremely high and variable loads. Therefore, this group of steels must withstand those loads for long times without breaking and without undergoing excessive wear or deformation. Tool steels are broadly divided into six categories: cold work, shock resisting, hot work, high speed, mold and special-purpose tool steels $[2,3]$. Among them, cold-work tool steels are the most important category, as they have a wide usage area in the industry because of their high hardness, toughness and wear resistance $[4,5]$. For a cold-work tool steel at a certain hardness, wear resistance may vary widely depending on the heat treatment used and wear mech- anism in the process [6]. Also, in higher carbon content steels such as cold-work tool steels, the martensite finish line temperature is below $0^{\circ} \mathrm{C}$, which means that at the end of the heat treatment, a low percentage of austenite is retained at room temperature. The retained austenite as a soft phase in steels could reduce the product life in working conditions [7].

Cryogenic treatment has been acknowledged for many decades as an effective method for increasing wear resistance in tool steels $[8,9]$. It is a one-time permanent treatment process, and it affects the entire cross section of the material usually done at the end of the conventional heat treatment process but before tempering. Also, it is not a substitute process but rather a supplement to the conventional heat treatment process [10]. According to the previous literature, two metallurgical phenomena are reported as the main reasons for using cryogenic treatment: firstly, the elimination of retained austenite, and secondly, the

*Corresponding author: tel.: +90 27222814 46; fax: +90 27222814 49; e-mail address: igunes@aku.edu.tr 
initiating of nucleation sites for subsequent precipitation of a large number of very fine carbide particles. In many cases, hardness increasing by about one to three Rockwell points has been claimed; however, some authors have reported a little increase in hardness values. There is little evidence concerning toughness changes [11].

Das et al. [12] examined the influence of cryogenic treatment $\left(-196^{\circ} \mathrm{C}\right)$ in between quenching and tempering on carbide precipitation and the tribological behavior of commercial AISI D2 steel. Experimental results showed that the cryogenic treatment of D2 steel markedly reduces the amount of retained austenite and makes significant changes in the precipitation behavior of secondary carbides and the formation of refined secondary carbides, increases their volume fraction and leads to a more uniform distribution of the carbides than those in conventionally heattreated D2 steel. Akhbarizadeh et al. [13] investigated wear behavior and hardness via a hardness tester and pin-on-disk wear testing machine. Results showed that deep cryogenic heat treatment improves the carbide percentage, distribution, hardness and wear resistance of 1.2080 (AISI D3) tool steel, as compared with those of the conventionally treated. Further improvements in the wear resistance and hardness were also observed due to the formation of some newly formed nano-sized carbides in the structure. Koneshlou et al. [14] studied the effects of low-temperature treatments on the microstructure, and mechanical properties of $\mathrm{H} 13$ hot-work tool steel. Cryogenic treatment at $-72{ }^{\circ} \mathrm{C}$ and deep cryogenic treatment at $-196^{\circ} \mathrm{C}$ were applied, and it was found that by applying the subzero treatments, the retained austenite was transformed to martensite. The deep cryogenic treatment also resulted in precipitation of more uniform and very fine carbide particles. The microstructural modification resulted in a significant improvement in the mechanical properties of the H13 tool steel. Li et al. [15] examined the effect on the microstructure and properties (hardness, toughness and the content of retained austenite) of a newly developed cold work die steel (Cr8Mo2SiV). Results showed that the hardness of the DCT (Deep Cryogenic Treatment) specimens was higher $(+0.5 \mathrm{HRC}$ to $+2 \mathrm{HRC})$ whereas the toughness was lower when compared with the conventionally treated specimens (quenching and tempering). After the DCT process, retained austenite transformed into martensite, although not completely. Oppenkowski et al. [16] studied the wear resistance of the powder metallurgically produced and cryogenically treated cold-work tool steel AISI D2. Further investigations of this study identified a nearly constant wear rate for holding times of up to $24 \mathrm{~h}$. The wear rate reaches a minimum for a longer holding time of $36 \mathrm{~h}$ and increases again with further holding.

The purpose of this study is to investigate the effects of deep cryogenic treatment $\left(-145^{\circ} \mathrm{C}\right)$ applied
Table 1. Chemical composition of Vanadis 4 tool steel

\begin{tabular}{cccccc}
\hline $\mathrm{C}$ & $\mathrm{Si}$ & $\mathrm{Mn}$ & $\mathrm{Cr}$ & $\mathrm{V}$ & $\mathrm{Mo}$ \\
\hline 1.4 & 0.4 & 0.4 & 4.7 & 3.7 & 3.5 \\
\hline
\end{tabular}

at three different holding times (1, 12 and $24 \mathrm{~h})$ to Vanadis 4 Extra cold-work tool steel, which has superior wear resistance to conventional tool steel AISI D2 die material [17]. For this purpose, some sliding wear tests were performed on a ball-on-disk wear testing device at two loads and two tempering temperatures.

\section{Materials and method}

Vanadis 4 cold-work tool steel rods with a diameter of $20 \mathrm{~mm}$ and height of $8 \mathrm{~mm}$ were used to prepare the samples. The chemical composition of the Vanadis 4 steel used is presented in Table 1. Samples were subjected to conventional heat treatment and cryogenic treatment in separate batches. The conventional heat treatment (CHT) consisted of hardening and tempering processes, which were conducted according to the ASM Heat Treater's Guide [18]. DCT was incorporated intermediately between hardening $(D)$ and tempering $(T)$; the details of each step are illustrated in Table 2 .

The cryogenic treatment was carried out by gradual cooling (approximate cooling rate of $1.5^{\circ} \mathrm{C} \mathrm{min}^{-1}$ ) of the samples to $-145^{\circ} \mathrm{C}$, and holding the samples at this temperature for different durations $(0,1,12$, and $24 \mathrm{~h}$ ), followed by gradual heating (approximate heating rate of $1.5^{\circ} \mathrm{C} \mathrm{min}^{-1}$ ) to room temperature. Cryogenically treated samples were tempered at two temperatures of 175 and $525^{\circ} \mathrm{C}$ for $2 \mathrm{~h}$. The samples subjected to different treatments are referred to henceforth with codes as shown in Table 2, where the numerals in the codes represent the time of holding in hours at $-145^{\circ} \mathrm{C}$. The contents of the retained austenite and martensite were measured using XRD, with a Bruker D8 Advance X-ray diffraction instrument that used a $\mathrm{Cr} \mathrm{K} \alpha \mathrm{X}$-ray source. From the X-ray diffractograms, the contents of the retained austenite and martensite were measured using ASTM E975 standard [19]. The bulk hardness (HRC) was measured using a Rockwell hardness tester with a load of $1.5 \mathrm{kN}$. The microstructure was characterized by a Leo $1430 \mathrm{VP}$ scanning electron microscope after etching in $4 \%$ Nital $(96 \mathrm{ml}$ ethanol and $4 \mathrm{ml} \mathrm{HNO}_{3}$ ).

\subsection{Wear experiments}

To perform the friction and wear of DCT samples, a ball-on-disk test device was used. In the wear 
Table 2. Different heat treatment cycles for the Vanadis 4 steel samples

\begin{tabular}{|c|c|c|c|c|c|c|}
\hline Samples & Hardening & $\begin{array}{l}\text { Cryogenic } \\
\text { treatment }\end{array}$ & Tempering & $\begin{array}{l}\text { Retained austenite } \\
\text { percentage }(\%)\end{array}$ & $\begin{array}{c}\text { Martensite } \\
\text { percentage }(\%)\end{array}$ & $\begin{array}{c}\text { Carbide } \\
\text { percentage }(\%)\end{array}$ \\
\hline CHT-LTT & Austenitizing at & None & & 14.1 & 74.37 & 11.53 \\
\hline DCT-1h-LTT & $30 \mathrm{~min}$ at $1030^{\circ} \mathrm{C}$ & $1 \mathrm{~h}$ at $-145^{\circ} \mathrm{C}$ & & 4.01 & 85.17 & 10.82 \\
\hline DCT-12h-LTT & and oil quenching & $12 \mathrm{~h}$ at $-145^{\circ} \mathrm{C}$ & $2 \mathrm{~h}$ at $175^{\circ} \mathrm{C}$ & 3.84 & 86.32 & 9.84 \\
\hline DCT-24h-LTT & & $24 \mathrm{~h}$ at $-145^{\circ} \mathrm{C}$ & & 3.53 & 87.20 & 9.27 \\
\hline CHT-HTT & Austenitizing at & None & & 2.93 & 82.98 & 14.09 \\
\hline DCT-1h-HTT & $30 \mathrm{~min}$ at $1030^{\circ} \mathrm{C}$ & $1 \mathrm{~h}$ at $-145^{\circ} \mathrm{C}$ & & 0.70 & 86.12 & 13.18 \\
\hline DCT-12h-HTT & and oil quenching & $12 \mathrm{~h}$ at $-145^{\circ} \mathrm{C}$ & $2 \mathrm{~h}$ at $525^{\circ} \mathrm{C}$ & 0.41 & 87.64 & 11.96 \\
\hline DCT-24h-HTT & & $24 \mathrm{~h}$ at $-145^{\circ} \mathrm{C}$ & & 0.25 & 89.01 & 10.74 \\
\hline
\end{tabular}

CHT - conventional heat treatment, DCT - deep cryogenic treatment, LTT - low tempering temperature, HTT - high tempering temperature
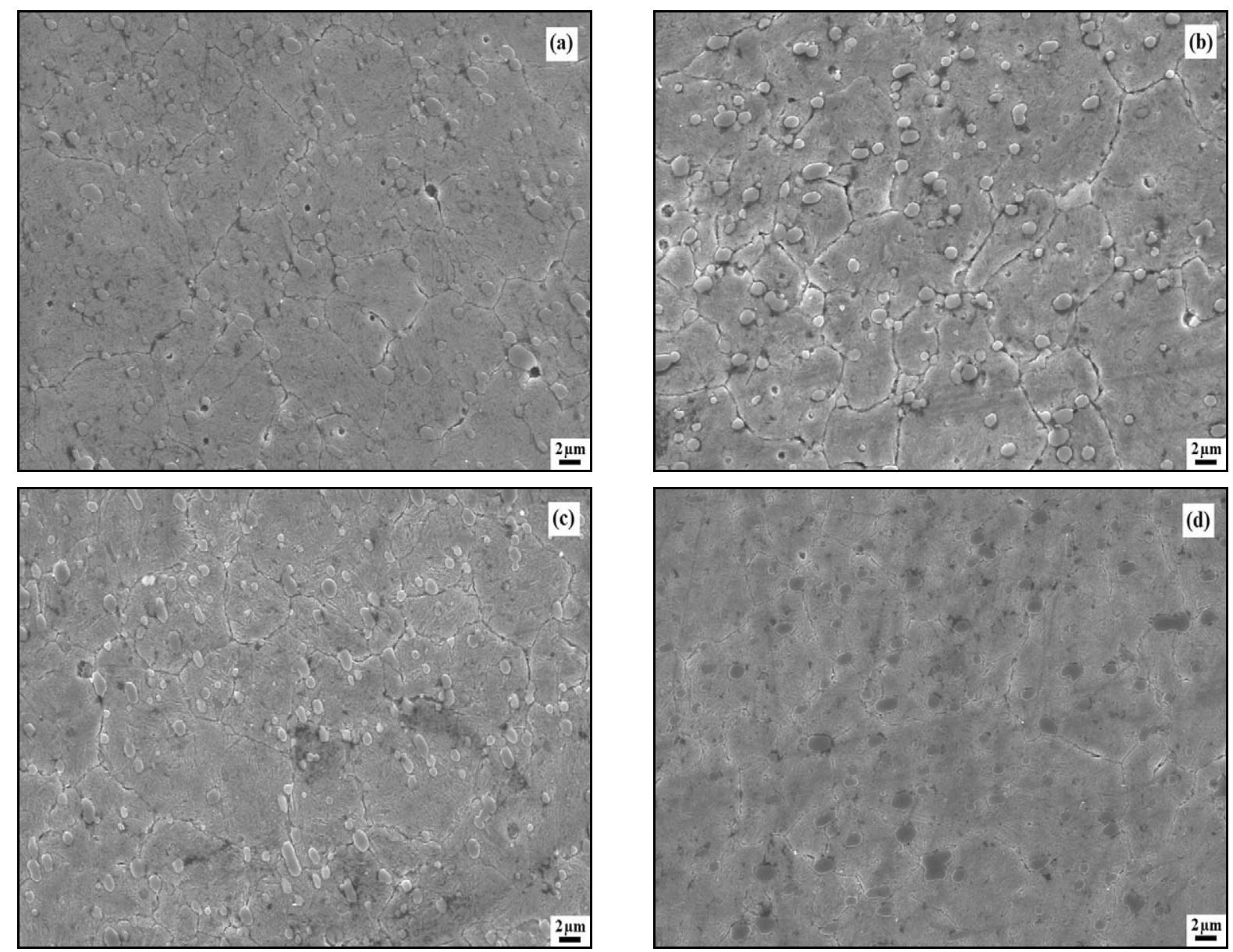

Fig. 1. SEM pictures of CHT and DCT samples tempered for $2 \mathrm{~h}$ at $175^{\circ} \mathrm{C}$ : a) CHT-LTT, b) DCT-1h-LTT, c) DCT-12h-LTT, d) DCT-24h-LTT.

tests, WC-Co balls of $8 \mathrm{~mm}$ in diameter supplied by H.C. Starck Ceramics GmbH were used. Errors caused by the distortion of the surface were eliminated by using a separate abrasion element (WC-Co ball) for each test. The wear experiments were carried out in a ball disk arrangement under dry friction conditions at room temperature with applied loads of $10 \mathrm{~N}$ and $20 \mathrm{~N}$ with a sliding velocity of $0.3 \mathrm{~m} \mathrm{~s}^{-1}$ at a sliding distance of $600 \mathrm{~m}$. In this way, each sample was tested twice. Before and after each wear test, each sample and abrasion element was cleaned with ethanol. After the test, the wear volumes of the samples were quantified by multiplying cross-sectional areas of wear by the width of the wear track obtained from the device, a Tribotechnic Rugosimeter. Wear rate $\left(\mathrm{mm}^{3} \mathrm{Nm}^{-1}\right)$ was calculated by the following formula (1): 

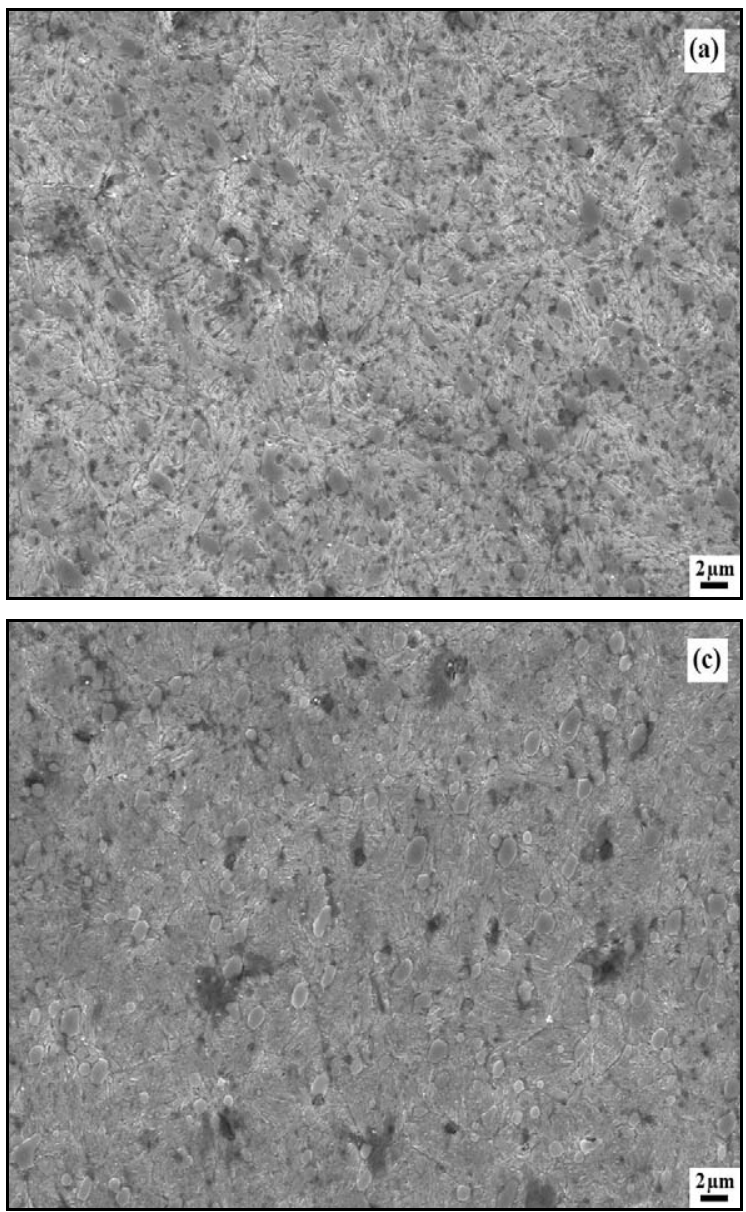
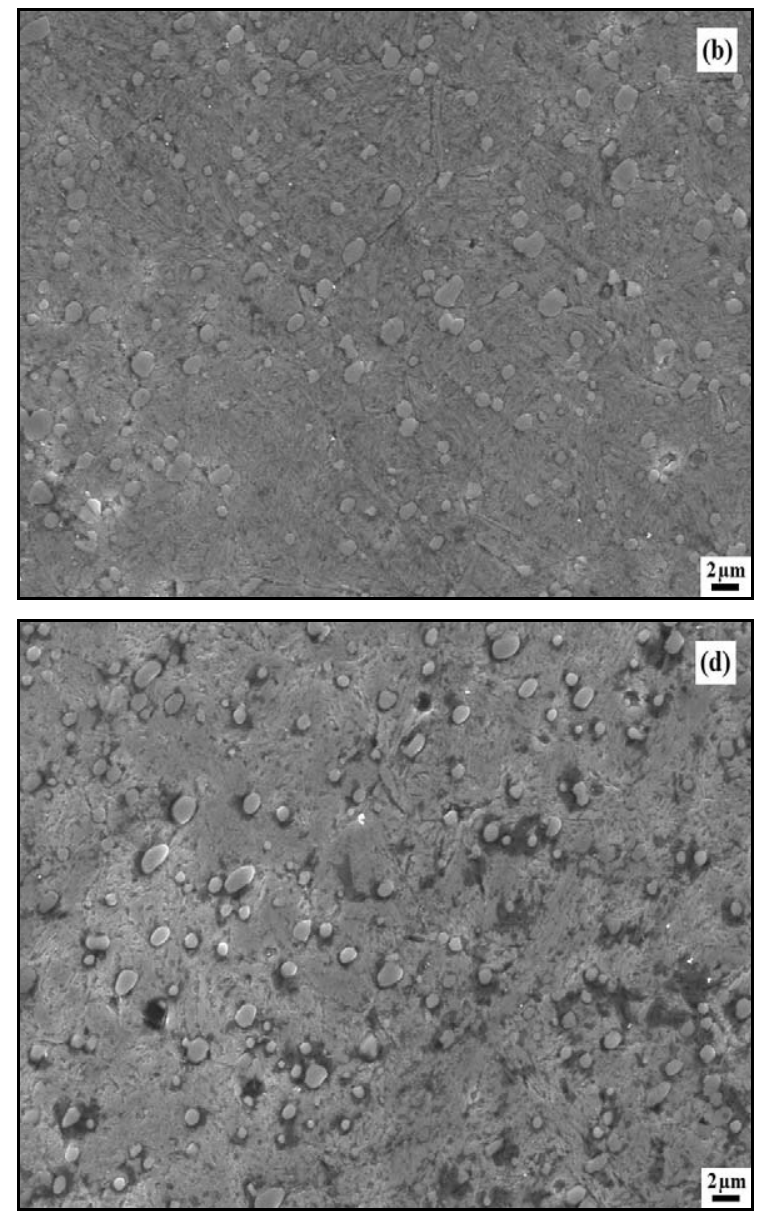

Fig. 2. SEM pictures of CHT and DCT samples tempered for $2 \mathrm{~h}$ at $525^{\circ} \mathrm{C}$ : a) CHT-HTT, b) DCT-1h-HTT, c) DCT-12h-HTT, d) DCT-24h-HTT.

Wear rate $=$ Worn volume $/($ Applied load $\times$ Sliding distance).

Friction coefficients depending on the sliding distance were obtained through the friction coefficient program. As a result of the wear tests, graphs of the friction coefficient, surface roughness and wear rate of DCT samples were plotted. Worn surfaces were investigated by scanning electron microscopy (SEM) and energy-dispersive X-ray spectroscopy (EDS).

\section{Results and discussion}

\subsection{Microstructure observations}

SEM pictures of CHT and DCT samples tempered at two different temperatures are shown in Figs. 1 and 2. These figures show that the SEM image of the undissolved carbide particles (white color) and massive regions around the carbides were probably austenite taken with backscattered electrons (BE).

After cryogenic treatment, the carbides became fine and distributed in a more homogeneous way. In particular, the finest carbide particles were formed and homogeneously distributed after DCT for $12 \mathrm{~h}$ (Figs. 1c, 2c) when compared to CHT and DCT for $1 \mathrm{~h}$ and $24 \mathrm{~h}$. There are non-homogeneous carbide particles of different sizes in the microstructure (Figs. 1 and $2 \mathrm{a}-\mathrm{d}$ ). These particles are fragmented and evolve into a more compact and homogeneous structure after cryogenic treatment and tempering. Figures $3 \mathrm{a}-\mathrm{d}$ show the XRD diffraction of the CHT and the DCT samples.

The peaks corresponding to martensite, retained austenite and carbides are visible. After DCT, the peaks of austenite have a low-intensity value. This indicates that the retained austenite has transformed to martensite during DCT. However, the transformation is not complete $[7,20]$. The results in Table 2 lead to the inference that the retained austenite percentage decreases with increasing cryogenic processing time and reaches maximum at DCT-24h samples tempered at $525^{\circ} \mathrm{C}$. The lowest retained austenite volume was obtained in the DCT-24h sample tempered at $525^{\circ} \mathrm{C}(0.25 \%)$ while the highest retained austenite volume was obtained in the CHT sample tempered at $175^{\circ} \mathrm{C}(14.1 \%)$. In the DCT samples, the retained 


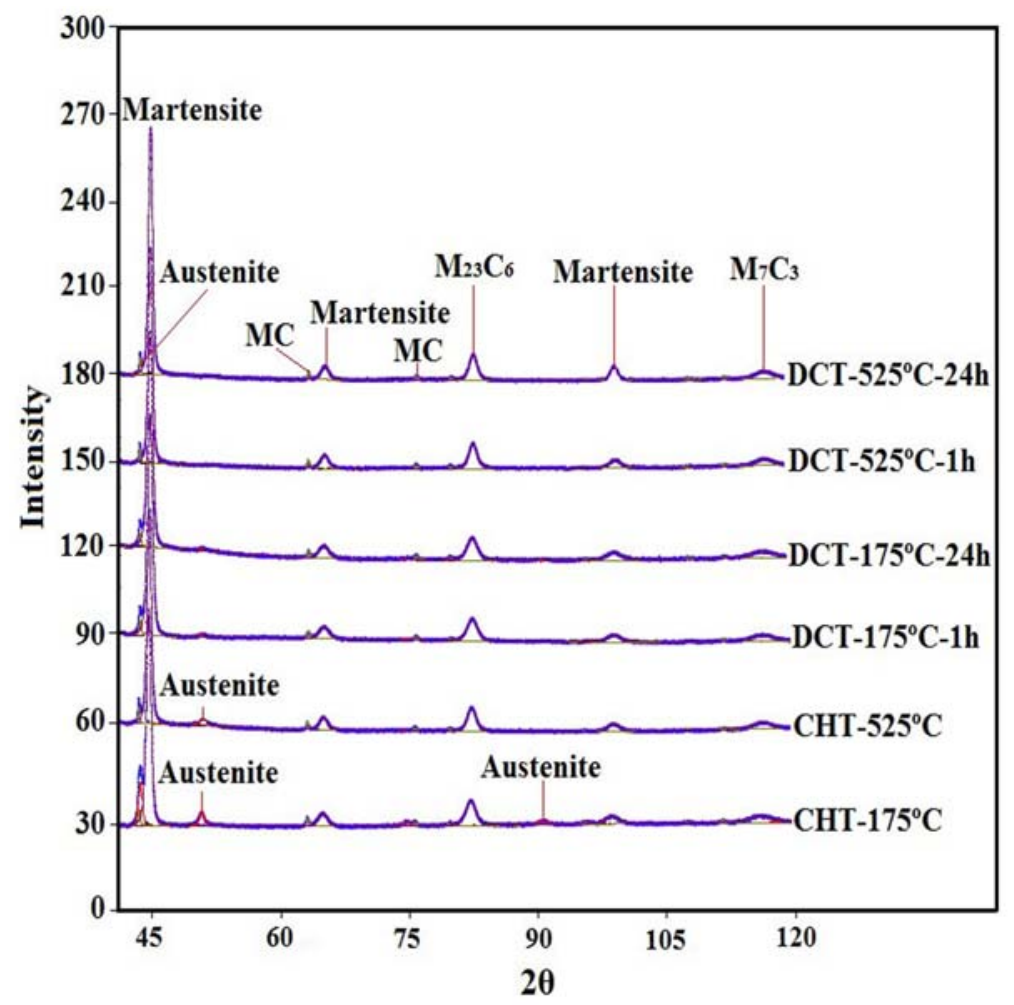

Fig. 3. The XRD diffraction of the CHT and the DCT samples.

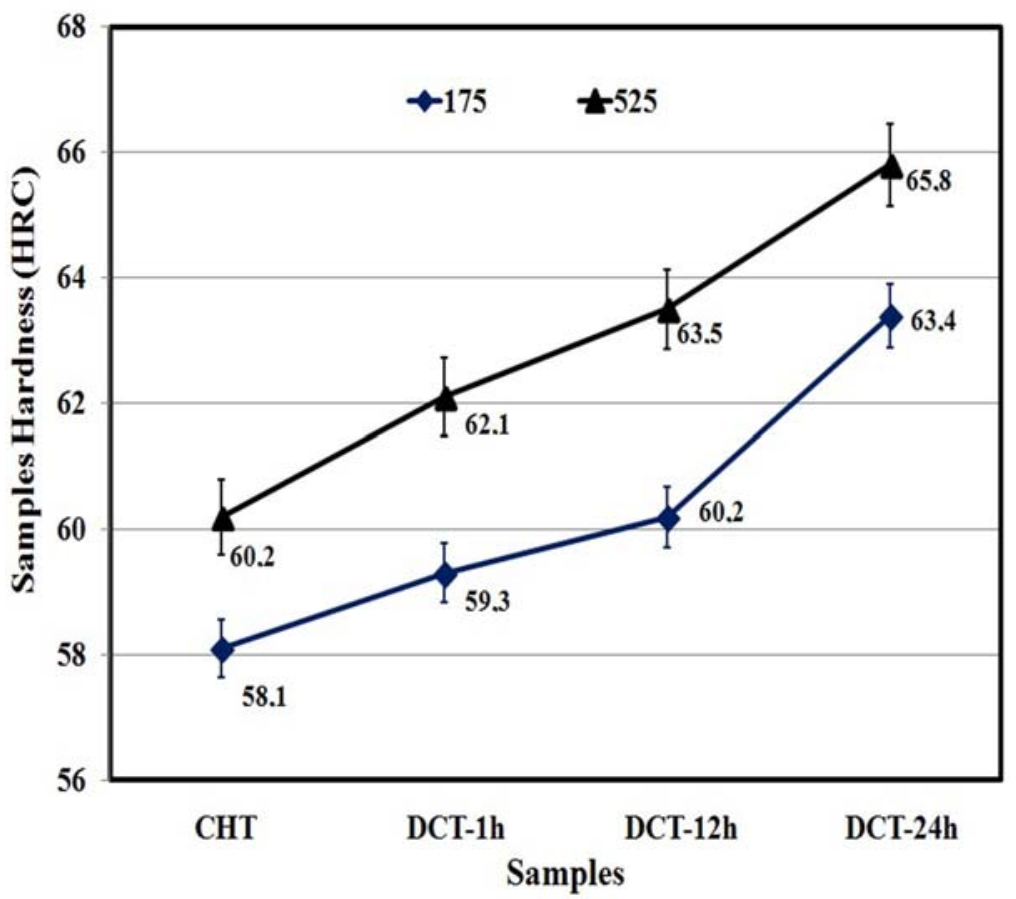

Fig. 4. The hardness of CHT and DCT samples.

austenite percentage is lower than in the CHT sample. Cryogenic treatment can effectively reduce the retained austenite content, but cryogenic treatment cannot make retained austenite transform to martensite completely [21]. In addition, it was observed from the amounts of retained austenite (Table 2) and hardness values (Fig. 4) that austenite amounts in the samples tempered at $525^{\circ} \mathrm{C}$ are lower than those in the sam- 


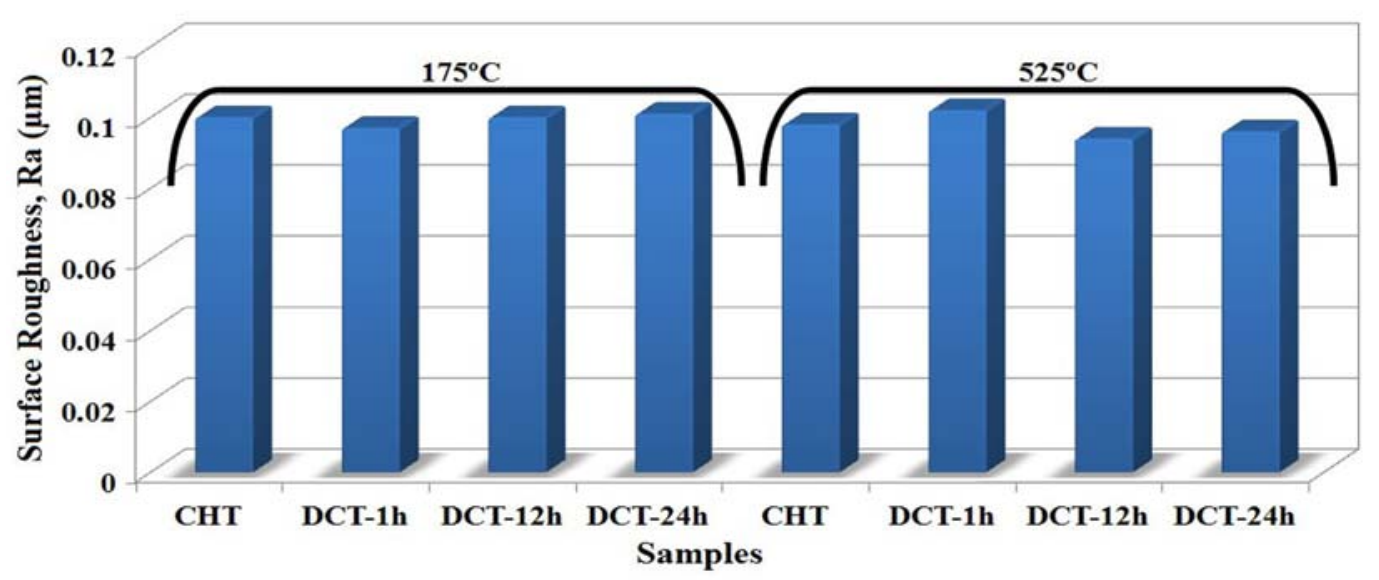

Fig. 5. Surface roughness values of CHT and DCT samples.

ples tempered at $175^{\circ} \mathrm{C}$, whereas the hardness of the samples tempered at $525^{\circ} \mathrm{C}$ is higher than that of the samples tempered at $175^{\circ} \mathrm{C}$. This case showed that a tempering temperature of $525^{\circ} \mathrm{C}$ was better than a tempering temperature of $175^{\circ} \mathrm{C}$ in terms of the maximal transformation of retained austenite to martensite and higher hardness values for Vanadis 4 Extra [22].

\subsection{Hardness}

The hardness test was carried out using the Rockwell $\mathrm{C}$ hardness tester. The results (Fig. 4) show that the cryogenic treatment increased the hardness. The samples that were cryo-treated show a further increase in hardness. The higher hardness of the DCT samples was due to the decrease in retained austenite. Also, in the DCT samples, the retained austenite was nearly eliminated at the tempering temperature of $525^{\circ} \mathrm{C}$, they had a more homogenized chromium carbide distribution, and increased hardness due to the higher chromium carbide percentage. The hardness results show that the DCT increases the hardness of the samples by approximately 6 HRC. The hardness of deep cryogenic-treated samples increases with increasing holding time at cryogenic temperatures, and reaches a maximum at a deep cryogenic processing time of $24 \mathrm{~h}$ (Fig. 4).

It can be said that the hardness value was affected by the precipitation process. In the longer holding times, the progress of the carbon segregation increases carbide precipitate sizes, thereby decreasing the number of carbides and their homogenized distribution. This is in agreement with the previous studies reported in the literature [23-26]. In this study, tempering was carried out at temperatures of 175 and $525^{\circ} \mathrm{C}$ for $2 \mathrm{~h}$ after the cryogenic treatment increasing the hardness of the tool steel and causing secondary carbide precipitation. These are among the most important factors for the improvements in the service life of tool steel. The microstructure and hardness investi- gations were conducted after the cryogenic treatment confirmed these changes (Fig. 4). Molinari et al. [27] and Pellizzari et al. [28] subjected tool steels to cryogenic treatment. They determined that the increase in tool life following the cryogenic treatment was due to the fact that the cryogenic treatment carried out after a CHT transformed the retained austenite in the structure of the cutting tools to martensite, improving the mechanical properties of the cutting tools, such as the hardness and wear resistance, by providing a more homogeneous distribution of carbides.

\subsection{Wear resistance}

Wear tests were carried out after all the samples had passed through the 1200 grid grinding stages. Therefore, prior to the wear process, surface roughness values of Vanadis 4 cold-work tool steel at different periods of time were observed to be similar (Fig. 5).

Friction coefficient values at different wear loads of the samples, cryo-treated at different periods of time, can be seen in Fig. 6. Friction coefficient values of the DCT samples increased as the amount of wear load increased. When the friction coefficient of the samples worn under a $20 \mathrm{~N}$ load was analyzed, the lowest and the highest friction coefficients were obtained from the DCT-24h-HTT and the CHT samples, respectively. The friction coefficient under a $10 \mathrm{~N}$ load ranged from 0.24 to 0.40 while the friction coefficient under a $20 \mathrm{~N}$ load was found to vary between 0.29 and 0.58 .

CHT and DCT Vanadis 4 samples were subjected to a wear process under 10 and $20 \mathrm{~N}$ loads. The results obtained from the wear tests performed on the samples are presented in Fig. 7. It was determined that the wear rates increased as the amount of applied load increased. When the samples worn under each load (10 and $20 \mathrm{~N}$ ) were examined, the highest wear rate was observed in the CHT-LTT sample, whereas the lowest wear rate was observed in the DCT-24h-HTT sample. The lowest wear rate of the DCT-24h-HTT sample can be attributed to increasing hardness (65.8 HRC) and 


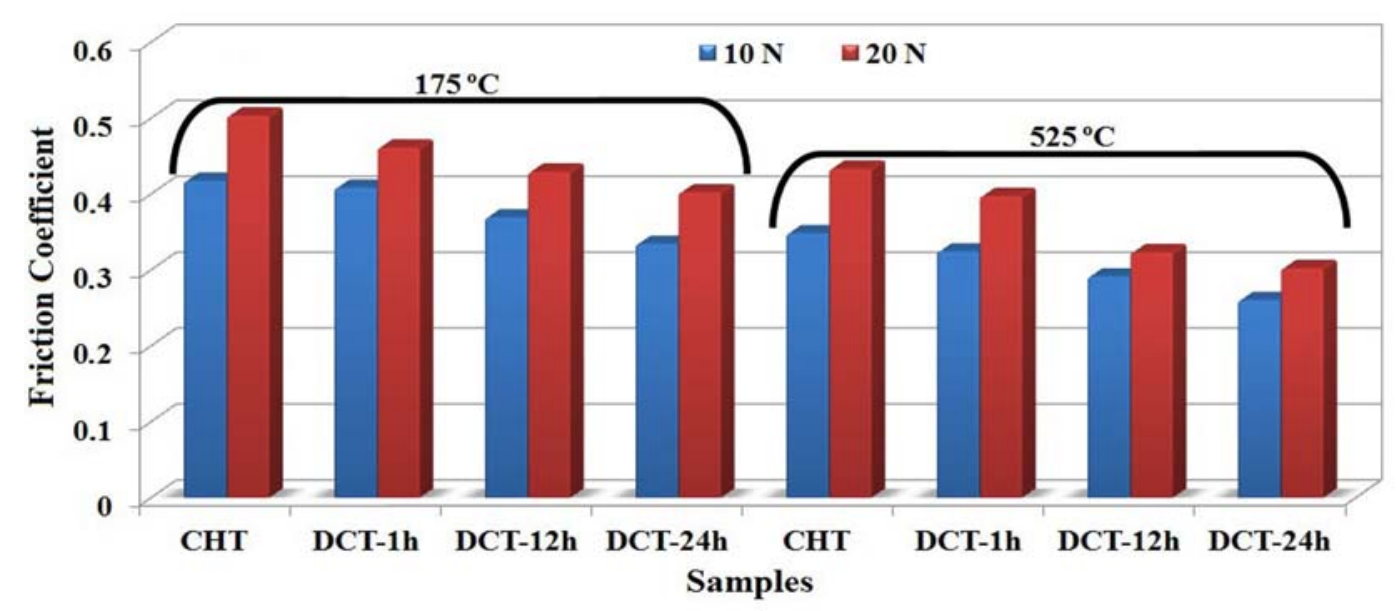

Fig. 6. Friction coefficients of CHT and DCT samples.

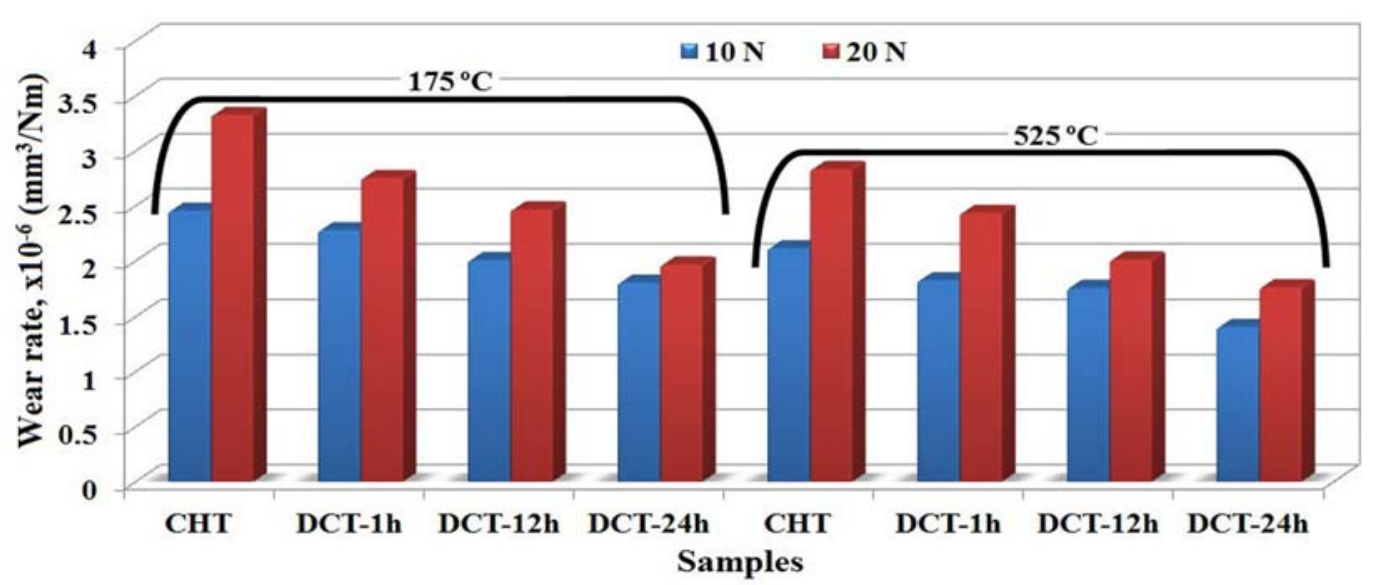

Fig. 7. Wear rates of CHT and DCT samples.

wear resistance due to the maximal transformation of retained austenite to martensite, the formation of fine carbide particles and homogeneous distribution of carbides (Fig. 2d).

While the wear rate of the CHT-LTT sample was $2.458 \times 10^{-6} \mathrm{~mm}^{3} \mathrm{~N}^{-1} \mathrm{~m}^{-1}$ under a $10 \mathrm{~N}$ load, it increased to $3.326 \times 10^{-6} \mathrm{~mm}^{3} \mathrm{~N}^{-1} \mathrm{~m}^{-1}$ as the load increased ( $36 \%$ ). The wear rate of the DCT-24h-HTT sample decreased to $1.402 \times 10^{-6} \mathrm{~mm}^{3} \mathrm{~N}^{-1} \mathrm{~m}^{-1}$ under a $10 \mathrm{~N}$ load. Lower wear rates were obtained from the DCT samples when compared to the CHT samples. It was observed that the DCT samples have a higher wear resistance. This can also be related to the presence of retained austenite in the structure and its transformation to martensite under the DCT as stated earlier. The most important effect of tempering on the DCT samples was improving the wear properties of the alloy. The better distribution of martensite laths, along with the more uniform and finer distribution of carbides, increased the wear properties, especially for longer times. Firouzdor et al. [11] investigated the effects of the cryogenic process on tool life during the drilling of the carbon steels at high speeds by M2 HSS drills. It was determined that the cryogenic process and the tempering process applied afterward achieved a 77 and $126 \%$ improvement in drill lives, respectively. Amini et al. [29] investigated the effect of holding time $(24-120 \mathrm{~h})$ at a liquid nitrogen temperature during the DCT on the microstructural changes of AISI D3 tool steel. They showed that the hardness, microhardness, microstructure uniformity and carbide percentage reached their optimum values with a $36 \mathrm{~h}$ holding duration. Gunes et al. [30] found that similar amounts of carbon and martensite in bearing steel (AISI 51200) increased the hardness values, consequently leading to an increase in wear resistance.

Enhancement of wear resistance by cryogenic treatment is attributed to the elimination of retained austenite, refinement of carbide particles, and their homogeneous distribution. The presence of numerous ultrafine carbides in cryo-treated steels assists in attaining the micro-stress distribution of the material in a way that results in favorable crack growth resis- 

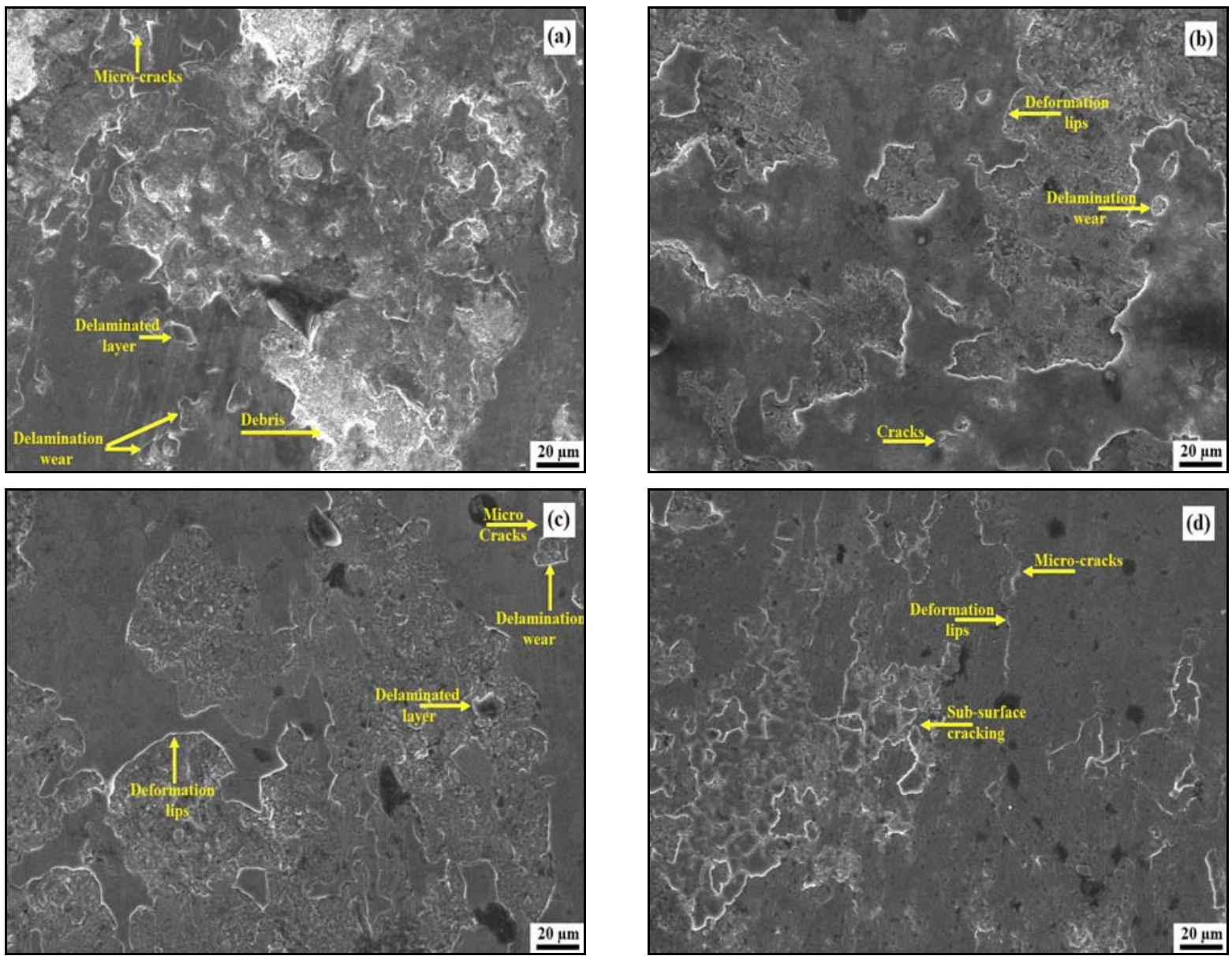

Fig. 8. SEM micrographs of the worn-out surfaces of samples tempered for $2 \mathrm{~h}$ at $175^{\circ} \mathrm{C}$ : a) CHT-LTT, b) DCT-1h-LTT, c) DCT-12h-LTT, d) DCT-24h-LTT samples.

tance of the material. This, in turn, leads to higher wear resistance [12].

SEM images of typically worn surfaces generated during wear tests of CHT, DCT $(1,12$, and $24 \mathrm{~h})$ tempered at $175^{\circ} \mathrm{C}$ and $525^{\circ} \mathrm{C}$ at a $20 \mathrm{~N}$ normal load and a sliding velocity of $0.15 \mathrm{~m} \mathrm{~s}^{-1}$ are shown in Figs. 8 and $9 \mathrm{a}-\mathrm{f}$, respectively. The wear mechanisms have been examined by analyzing the morphology of the worn-out surfaces of the CHT and DCT samples. The morphologies present deformation lips, micro-cracks, and delamination characteristics, as marked by arrows. The SEM micrograph of the worn-out surfaces of the samples (Figs. 8 and 9) shows that the predominant wear mechanism is delamination. The worn-out surface of the DCT samples shows a smoother surface than the CHT samples. The DCT samples exhibit fewer ridges; typically the worn surface roughness of the DCT-24h sample is the lowest among all samples (Figs. 8d and $9 d)$. This can be attributed to the formation of fine carbide particles because they lead to less surface damage during wear testing. The wear mechanisms were examined by analyzing the morphology of the worn-out surfaces of the DCT samples and the collected wear debris generated during the stable wear regime. Nature, size and morphology of the wear debris generated during wear tests of the DCT samples are shown in Figs. 8 and $9 \mathrm{~b}-$ d. It was observed that micro-cracks formed on the sample surface and degraded as a result of wear (Fig. 9d). In Figs. 8 and 9ac, delamination wear with the advancement of microcracks was observed in the wear tracks of the CHT, DCT-1h, and DCT-12h samples. EDS (Energy Dispersive X-ray Spectrometry) analysis of points A and $\mathrm{B}$ in Figs. $8 \mathrm{~d}$ and $9 \mathrm{~d}$ are given in Figs. 10a,b. No oxidation was observed on the surfaces of the samples after the wear tests (Fig. 9). The reasons behind this might be the low shear rate and the cleaning of the surfaces of the samples in an ultrasonic bath after the wear tests.

\section{Conclusions}

The effects of DCT on the wear behavior, hardness, and microstructure of Vanadis 4 cold-work tool steel, which were cryo-treated for different holding times, were studied. The results obtained can be summarized as follows: 

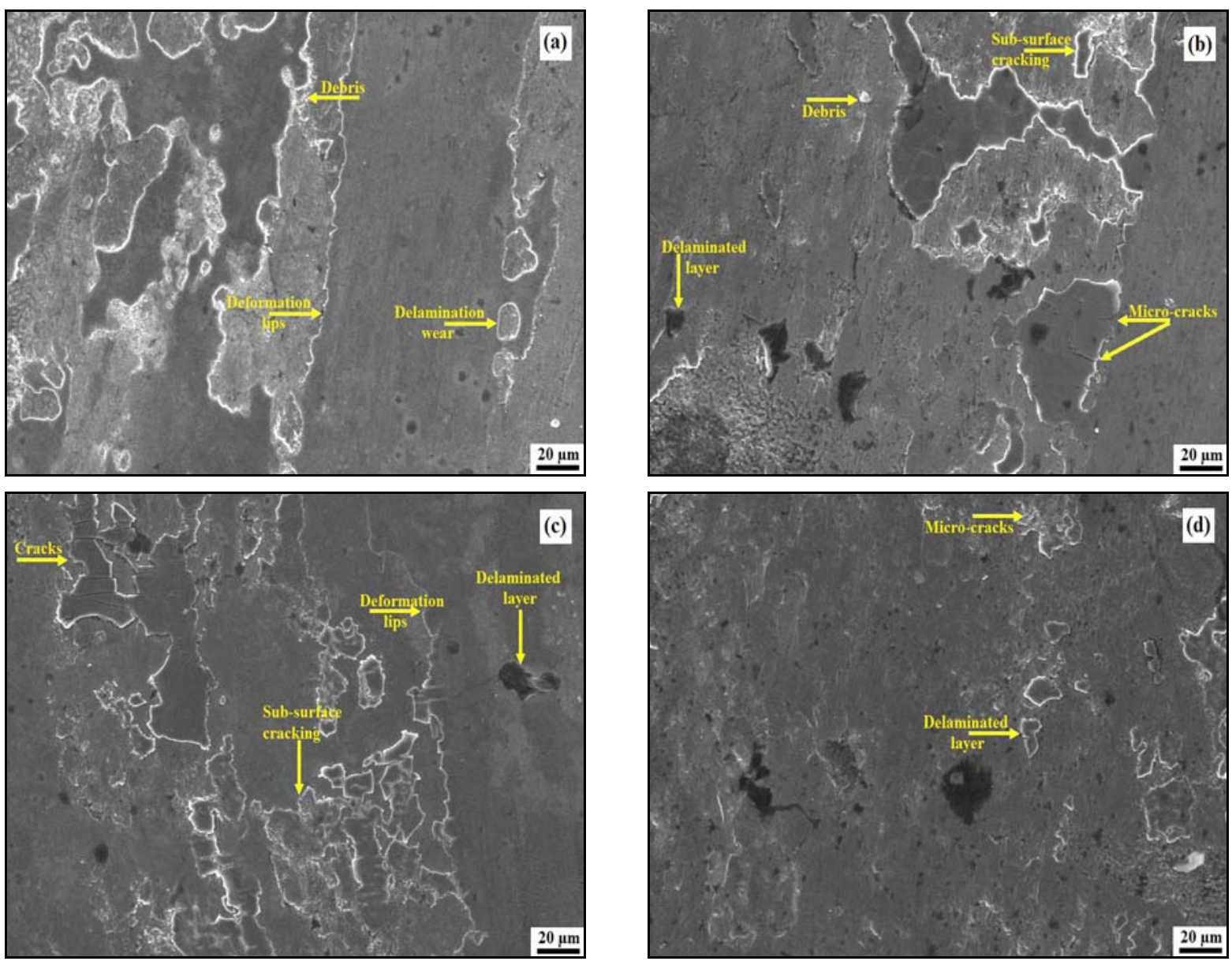

Fig. 9. SEM micrographs of the worn-out surfaces of samples tempered for $2 \mathrm{~h}$ at $525^{\circ} \mathrm{C}$ : a) CHT-HTT, b) DCT-1h-HTT, c) DCT-12h-HTT, d) DCT-24h-HTT samples.
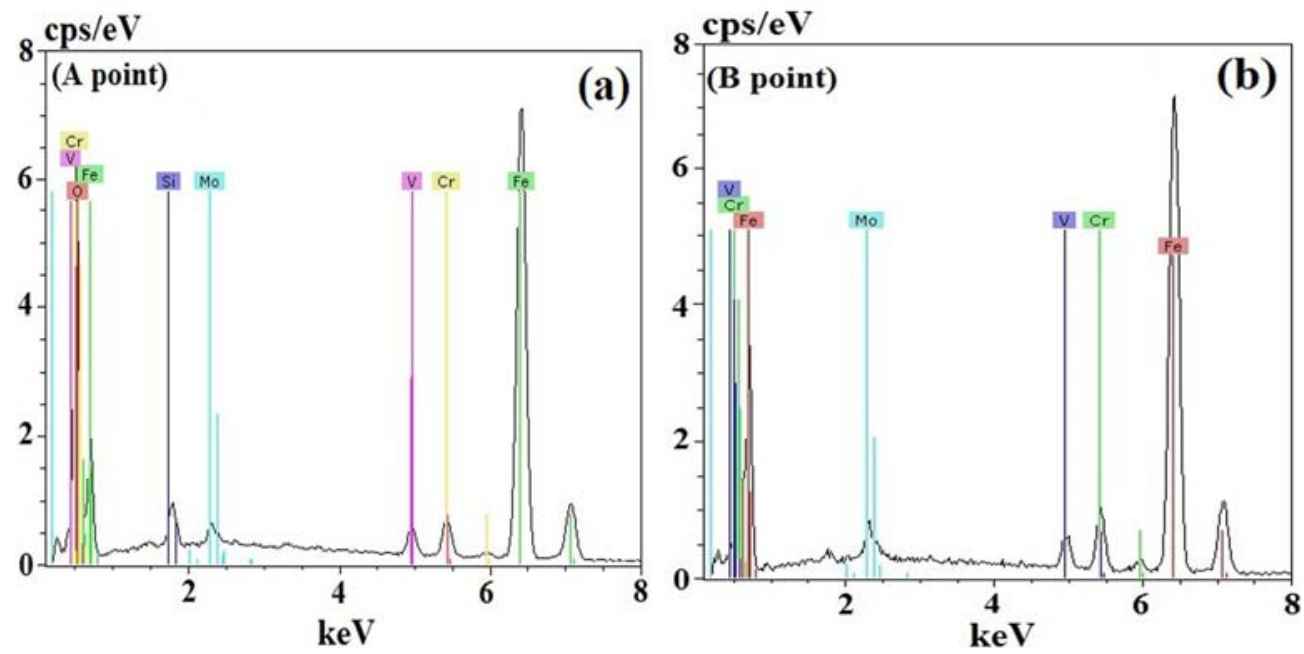

Fig. 10. EDS analysis of the worn-out surfaces of the CHT and DCT samples.

- The DCT created a more homogeneous carbide distribution with a more uniform particle size and some newly formed small-sized carbides. It was shown that the microstructure of the DCT samples was changed by varying the holding duration.
- The cryogenic process increased the redistribution of chromium carbides in the microstructure, the transformation of austenite to martensite and the hardness of the samples; this, in turn, led to an increase in the wear resistance of the Vanadis 4 steel. 
- The highest wear rate was observed in the samples worn under loads of 10 and $20 \mathrm{~N}$ in CHT samples, while the lowest wear rate was observed in the DCT$-24 \mathrm{~h}$ samples tempered at $525^{\circ} \mathrm{C}$ due to the maximum transformation of retained austenite to martensite, the formation of finer carbide particles and the homogeneous distribution of carbides after DCT.

- Delamination wear with the advancement of micro-cracks was observed in the wear tracks of the DCT samples.

- It was observed that a high tempering temperature was more effective than deep cryogenic treatment in the transformation of austenite retained in the microstructure of Vanadis 4 tool steel to martensite.

\section{Acknowledgements}

The authors are thankful to the Atilim University (Turkey) Metal Forming Center of Excellence and Scientific Research Project (13.FEN.BİL.48) Council of Afyon Kocatepe University for their support of this work. This article was based on Mustafa Uzun's master thesis.

\section{References}

[1] Roberts, G., Krauss, G., Kennedy, R: Tool Steels. 5th Edition. Materials Park, ASM International 1998.

[2] Paydar, H., Amini, K., Akhbarizadeh, A.: Kovove Mater., 52, 2014, p. 163.

[3] Bourithis, L., Papadimitriou, G. D., Sideris, J.: Tribology International, 39, 2006, p. 479. doi:10.1016/j.triboint.2005.03.005

[4] Roberts, G. A., Cary, R. A.: Tool Steels. 4th Edition. Materials Park, ASM International 1980.

[5] Glaeser, W. A.: Materials for Tribology. Tribology Series. Vol. 20. Amsterdam, Elsevier 1992.

[6] Kalsi, N. S., Sehgal, R., Sharma, V. S.: Mater. and Manuf. Process., 25, 2010, p. 1077. doi:10.1080/10426911003720862

[7] Arslan, F. K., Altinsoy, I., Hatman, A., Ipek, M., Zeytin, S., Bindal, C.: Vacuum, 86, 2011, p. 370. doi:10.1016/j.vacuum.2011.07.066

[8] Paulin, P.: Gear Technol., 10, 1993, p. 26.

[9] Mohan, L. D., Renganarayanan, S., Kalanidhi, A.: Cryogenics, 41, 2001, p. 149. doi:10.1016/S0011-2275(01)00065-0

[10] Bensely, A., Prabhakaran, A., Mohan, L. D., Nagaraja, G.: Cryogenics, 45, 2005, p. 747. doi:10.1016/j.cryogenics.2005.10.004

[11] Firouzdor, V., Nejati, E., Khomamizadeh, F.: J. Mater. Process. Technol., 206, 2008, p. 467. doi:10.1016/j.jmatprotec.2007.12.072
[12] Das, D., Dutta, K., Toppo, V., Ray, K. K.: Mater. and Manuf. Process., 22, 2007, p. 474. doi:10.1080/10426910701235934

[13] Akhbarizadeh, A., Javadpour, S., Amini, K.: Materials and Design, 45, 2013, p. 103. doi:10.1016/j.matdes.2012.08.012

[14] Koneshlou, M., Asl, K. M., Khomamizadeh, F.: Cryogenics, 51, 2011, p. 55. doi:10.1016/j.cryogenics.2010.11.001

[15] Li, S., Xie, Y., Wu, X.: Cryogenics, 50, 2010, p. 89. doi:10.1016/j.cryogenics.2009.12.005

[16] Oppenkowski, A., Weber, S., Theisen, W.: J. Mater. Process. Technol., 210, 2010, p. 1949. doi:10.1016/j.jmatprotec.2010.07.007

[17] Cora, O. N., Koc, M.: International Journal of Machine Tools and Manuf., 49, 2009, p. 897. doi:10.1016/j.ijmachtools.2009.07.003

[18] Unterweiser, P. M., Boyer, H. E., Kubbs, J. J. (Eds.): Heat Treater's Guide: Standard Practices and Procedures for Steel. 4th Editon. Metal Parks, ASM 1987.

[19] ASTM E975-00, Standard Practice for X-Ray Determination of Retained Austenite in Steel with Near Random Crystallographic Orientation. ASTM Book of Standards. West Conshohocken, ASTM 2004.

[20] Li, S., Deng, L., Wu, X., Min, Y., Wang, H.: Cryogenics, 50, 2010, p. 754 . doi:10.1016/j.cryogenics.2010.09.002

[21] Wang, J., Xiong, J., Fan, H., Yang, H. S., Liu, H. H., Shen, B. L.: J. Mater. Process. Technol., 209, 2009, p. 3236. doi:10.1016/j.jmatprotec.2008.07.035

[22] http://www.uddeholm.com/files/PB_Uddeholm_ vanadis_4_ extra_english.pdf

[23] Podgornik, B., Majdic, F., Leskovsek, V., Vizintin, J.: Wear, 288, 2012, p. 88. doi:10.1016/j.wear.2011.04.001

[24] Das, D., Dutta, A. K., Ray, K. K.: Cryogenics, 49, 2009, p. 176. doi:10.1016/j.cryogenics.2009.01.002

[25] Darwin, J. D., Lal, D. M., Nagarajan, G.: J. Mater. Process. Technol., 195, 2008, p. 241. doi:10.1016/i.jmatprotec.2007.05.005

[26] Li. S., Xie, Y., Wu, X.: Cryogenics, 50, 2010, p. 89. doi:10.1016/j.cryogenics.2009.12.005

[27] Molinari, A., Pellizzari, M., Gialanella, S., Straffelini, G., Stiasny, K. H.: J. Mater. Process. Technol., 118, 2001, p. 350. doi:10.1016/S0924-0136(01)00973-6

[28] Pellizzari, M., Molinari, A.: In: Proceedings of 6th International Tooling Conference. Eds.: Bergström, J., Fredriksson, G., Johansson, M., Kotik, O., Thuvander, F. Karlstad, Karlstad University 2002, p. 547.

[29] Amini, K., Nategh, S., Shafyei, A.: Materials and Design, 31, 2010, p. 4666 doi:10.1016/j.matdes.2010.05.028

[30] Gunes, I., Cicek, A., Aslantas, K., Kara, F.: Trans. Indian Inst. Met., 67, 2014, p. 909. doi:10.1007/s12666-014-0417-4 